\title{
Quality Analytics Led Human Resource Management and Its Impact on Customer Satisfaction
}

\author{
IMRAN AHMAD RANA \\ $\mathrm{Ph} . \mathrm{D}$. Scholar, Superior University, Lahore. \\ Email: qsipak@hotmail.com \\ MUHAMMAD ALI YAB \\ Ph.D. Scholar at Superior University, Lahore.
}

\section{CH. ABDUL REHMAN}

Chairman and Professor, Superior University, Lahore.

\begin{abstract}
The study was conducted to determine the mediating role of Quality Management Analytics (QMA) between selected Human Resource Management (HRM) and Customer satisfaction in service sector of Punjab, Pakistan. The purpose of quantitative study was to assess the association between HRM, QMA and Customer satisfaction in service sector organizations. Data was collected from 400 employees working in six selected cities of the Punjab province. This study provided the guidance to service sector organizations of Punjab to implement the quality management analytics led human resource management practices and know its impact on customer requirements service satisfaction. The study revealed that human resource management practices when coupled with quality management analytics support in enhancing satisfaction of customers. It was found that employees generally want to improve the quality of their services but limited analytics resources are available to instantly analyze and guide on issues wherever required. So, it was recommended to integrate quality management analytics practices with HRM cells to improve the quality of services on continual basis. The research study was limited to service sector organizations operating in selected cities of one province. Future studies should examine the status at other sectors in different regions of Pakistan. The sample size should be increased as well so we can generalize the findings across the Pakistan.
\end{abstract}

Keywords: HRM, Quality Management, Analytics, Customer Satisfaction.

\section{Introduction}

The use of technology and technological applications to manage routine operations of organizations has witnessed considerable increase during that past few years. So, advance technological applications are being implemented by businesses and public sector companies in order to quickly access and analyze data to ensure operational improvement at all fronts. Beside improving operation such technological professions are contributing their best to develop the economy of country by generating the employment (Sharma et al., 2019). The service sector organizations are globally supporting in adding more job opportunities as well as adding to their sectoral growth. Traditionally service sector have known to be performing their activities manually but from last decade the transactions are now being done through software application even at small outlets (Liu at al., 2020). Likewise, traditional HR system had many problems like employee data security issues, extra man power requirements, enhanced time in executing activities and over burden to manage people data. Now, the modern tech system are diminishing all such problems by integrating analytics with HRM practices because HRM practices are playing significant role to increase the efficiency 
and effectiveness of employee efforts in order to attain the desired output (Martin et al. 2017). Currently analytics is being integrated through many sophisticated application to process entered data and retrieve useful information by considerably reducing employee work load.

At HR functions, employee performance appraisals are in practice since ages, likely collecting and analyzing HR performance measurements against pre-defined objectives is also in practice for the last many years. Fitz-Enz, (2014) in his study pointed out that the application of analytics in people management areas is still scare as compared with other disciplines i.e. risk management, marketing, supply chain and finance. Businesses are now forced to actively start the application of analytics in order to better predict future performance through a combination of statistics, management sciences, decision modelling and data mining techniques (Hassouna et al., 2015).

Past studies by Alina-Rodica (2019), Majumdar, (2016) and Ahmed et al. (2020) has discussed the role of quality management system practices to improve stature of human resource management system activities in organizations. Quality management or companywide quality control activities are improving processes in all sector and industries.

The current study was conducted with the objective to know the impact of quality analytics supported human resource management system on overall satisfaction of the service sector customers in the selected region. Quality management analytics' variables like plan, operation and delivery analytics were chosen to add value to the combined HRM practices (recruitment, development and appraisal).

The Objectives of this study were:

1 To determine the impact of HRM practices on customer satisfaction.

2. To determine the impact of Quality Management Analytics (QMA) practices on customer satisfaction

3. To determine the mediation effect of Quality management Analytics (BA) between HRM and customer satisfaction.

The study is significant in the number of ways: Firstly it will help to raise the quality analytic tools awareness of HRM professionals working across services sector which is currently known at lower level of introducing improvement projects (Liu at al. 2020). The issue identified in Pakistani service sector organisations is quality analytics and HRM practices are not fully implemented. HR planning, operation execution and service delivery process parameter have been found neglected (Ahmed, 2020 and Ahmad, 2019). So, this study will help spur the growth of HRM profession by way of quality management and analytics practices.

The study will respond to following research questions;

1) Do HRM practices linked with business analytics practices?

2) Do quality management and analytics practices are linked with customer satisfaction?

3) Do the HRM practices through QMA practices have same effect on customer satisfaction?

\section{Literature Review}

\section{Human_Resource_Management (HRM)}

HRM deals with the people issues (hiring, compensation, training performance management, organizational development, safety, wellness etc.). There is no agreed upon definition of the HRM, as per David, (2013) HRM is a bunch of system, practices and policies that support adequate working by people in certain entity likely Shahnawaz (2006) is of the view that HRM is a collection of decisions and practices that inspire people in a company. Burma (2014) pointed out that HRM is a planned system and strong method to guide 
and nurture organization's valued asset. Bhat and Reddy concluded HRM in 2006 as overall decisions made by the leadership that influence working and people performance. So, it can be said that HRM comprise on certain practices, policies and decision that in some sort or other affect employee performance. In the current study four people management practices were selected that mainly make up human resource management (Burma 2014) i.e recruitment, employee training, benefits and performance appraisal. The selected practices were discussed both in service operations and production environment. Longenecker and Fink (2013) elaborated that great challenge for HR leaders in changing times will be attract, pick and retain the required competence holders . Next comes in the activity of developing core skills as per prevailing context of the organisation under the futurist approach. In 2019 Dessler informed five phases of the training system where first is to pinpoint core job skills that in every case is considered essential. Second phase comprise on selecting the content and mechanism that content will be adequately delivered. Third point covers validation of step 2 where gaps to the content and delivery mechanism, practicality of the methods selected are tested by engaging closely with trainees. In fourth stage development activity is implemented at the focused individuals. Last phase covers evaluation process where the outcome is measured against the set objectives.

Gopinath and Shibu (2016) who discussed employee benefits as the financial package provided to the people to buy and match their commitment with desired level of firm performance. Organizations globally meet their goals and enhance competitive value as well as better ensure customer satisfaction though a customized reward package (Beck-Krala and Scott 2014). It has been discussed that only adequate reward system help hold people for longer times. So, benefits package proved to be a promising tool developing desired people behavior within a service sector.

Objectives of good performance appraisal systems are to guide, nurture daily activities of people and align those toward achieving organizations short and long term goals (Dessler 2019). Therefore, employee performance appraisal support in developing proper bonding amongst human resources and their employers. According to Gopinath (2016) performance appraisal is a closely knitted process to assess people performance as per some predefined criteria.

\section{Quality_Management \& Analytics (QMA)}

Quality management and Analytics contributions are owing to the years of work from multiple expert and gurus like Deming, Juran, Crosby, Shoji Shiba, Kano and very recently James Evans and Gary Cockins (Pambreni et al. 2019). So, the QMA discipline was not evolved as a result of contributions from a single group or area. Each of study was backed by the objective either to enhance productivity, quality and profitability. In 2016 Goetsch explained that quality management is such an approach of executing business which enhance competitiveness of the firm by way of gradual improvement to its processes, activities, people and products. Citing various studies Pambreni. et al. 2019 discussed that there are at least elven major quality management practices i.e. customer focus, commitment, strategic management, training and development, purpose of the organization, continual improvement, employee engagement, empowerment, process performance management, risk management, teamwork etc. The elements selected for the study were planning analytics, operation analytics and performance delivery analytics.

Professionals have always been found to be improving their planning processes accuracy by way of analytics integration in day to day activities. This has improved to better focus on market requirements as well as accurately meeting end user and intermediary chain's customer needs through analyzing data at plan stage (Hindle et al., 2016). Same is true for integrating the analytics base for gradual improvement at service operation or overall processes performance and reducing time to market by improving performance of dispatch operations (Trkman et al. 2010). The application of analytics at service operations has supported in increasing process effectiveness through reducing wastages and enhancing service delivery experience. (Hindle et al., 2016). 


\section{Customer Satisfaction}

Pambreni et al., (2019) discussed in their study customer satisfaction pertain to the degree by which a product or service delivered by an organization has met or exceeded the base requirements of a particular customer. Alina-Rodica, (2019) is of the view that it's the service or product quality factor that led to enhancing customer satisfaction or other way round develop dissatisfaction. Goetsch (2016) narrated in is study that under quality management perspective customer has been found to be the driver for any change. So, the satisfaction of all sorts of customers organizations are required to adequately assess the need of particular customer and then manage in complying with identified requirements. The origin of any quality related research starts from customer relationship management across various defined performance indicators (Hassouna et al., 2015). The organizations managing this successfully has been found to be ensuring survival for all stakeholders in one way or other. SO, the must requirement valid in the digital age too is to touch upon customer on a regular basis to enquire about level of their satisfaction and any emerging requirement or need that company must abide by (Ekawati, 2019). Under quality management scenario, the performance of organization found depended upon four major pillars where customer focus is the core activity.

\section{Research Model}

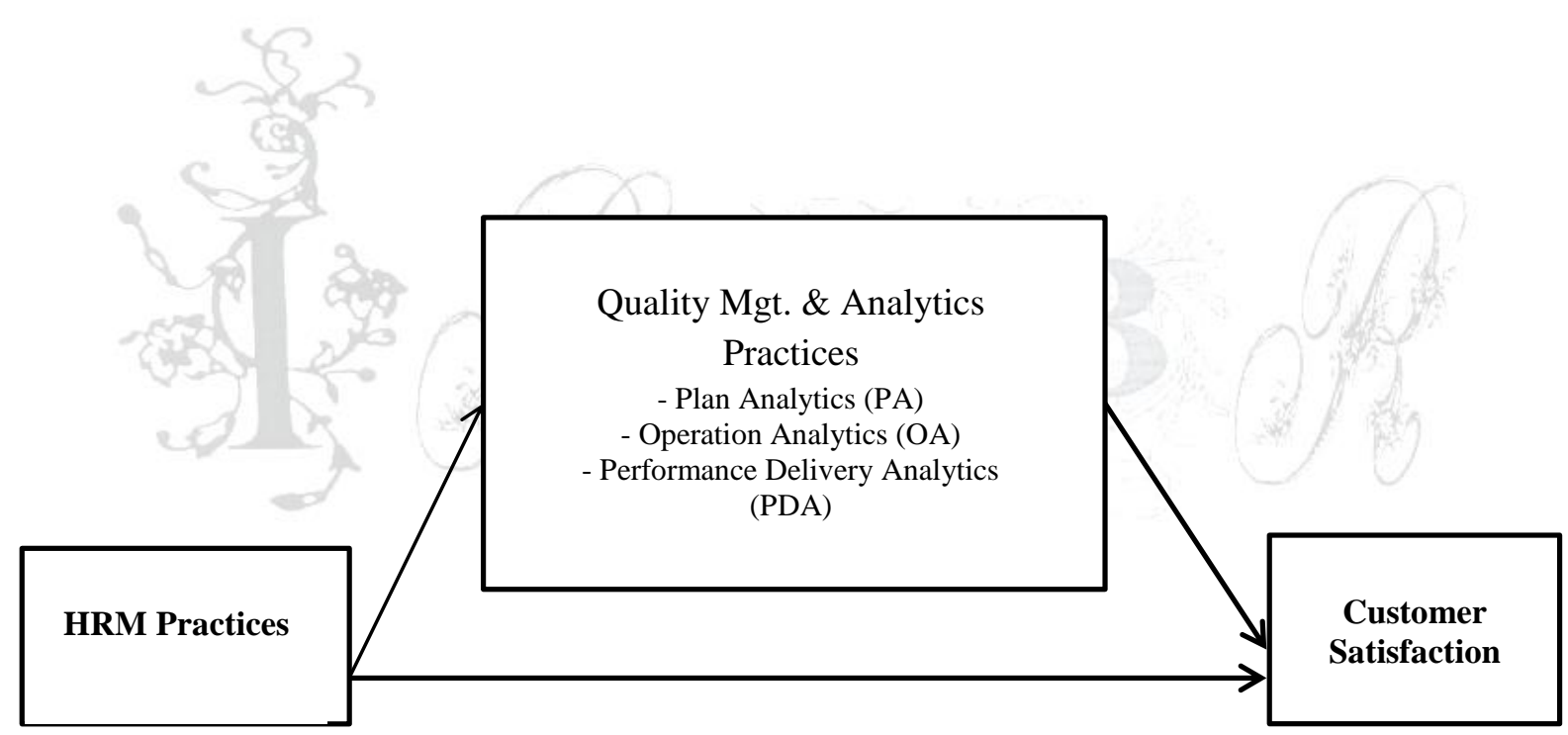

\section{Hypothesis}

H1: Human Resource management has positive impact on customer satisfaction

H2: Human Resource management has positive impact on Quality Management \& Analytics Practices

H3: Quality management \& Analytics has positive impact on customer satisfaction

H4: Quality Management \& Analytics mediates the positive relationship between human resource management and customer satisfaction management

\section{Research Methodology}

Population selected for the subject study includes employees of service sector organizations who are working in management and senior non-management cadres and managing daily operations or dealing with any type of their customers or involved in customer service delivery operations. The data was collected 
from employees who at least have two years' work experience in service sector companies. Structured questionnaires developed with a seven point likert scale were distributed through email and social media channel link (Linkedin, Facebook) to 400 front line officers and managers. The sample was chosen applying cluster sampling approach as the cities were truly the independent clusters associated with different industries in the area.

Target respondents working in six selected cities of the Punjab province (Rawalpindi, Gujranwala, Lahore, Faisalabad, Multan and Bahawalpur) were constantly followed up on daily basis through WhatsApp, sms etc. 312 questionnaires were received from the respondents. Only 302 questionnaires complying base requirements were utilized in this the study.

\section{Analysis and Results}

The goal of this section was to analyze the collected data. As narrated earlier, objective of data collection was to evaluate the mediating role of Quality Management and Analytics (QMA) practices between human resource management and satisfaction of customers in different service sector organizations. Table 1 highlight that the VIF values for the given predictors of study were less than 5 , as recommended by J. F. Hair et al. (2011); so, the this displays that no issue of multicollinearity exist in this study.

Table 1: Multicollinearity

\begin{tabular}{|lll|}
\hline Constructs & VIF & VIF \\
\hline & Quality Analytics & $\begin{array}{l}\text { Customer } \\
\text { Satisfaction }\end{array}$ \\
\hline HRM & 4.0263 & 3.618 \\
\hline
\end{tabular}

\section{Descriptive Statistics and Data Normality}

Table 2 discuss the descriptive statistics where the mean values of human resource management, Quality management \& analytics and customer satisfaction were 5.217, 5.186 and 5.624 respectively. PLS-SEM technique was used in this study as the benefits of using PLS-SEM approach is, it deals with non-normal conditions in data and there left no requirement comply with the normality assumption in PLS-SEM. In this study normality of the data was assessed through Skewness, Kurtosis and histogram plots. The outcome described in the table shows that the data of study was not normally distributed, so PLS-SEM can be applied. (Bontis, Booker, \& Serenko, 2007).

Table 2: Descriptive Statistics

\begin{tabular}{|lcccr|}
\hline Constructs & Mean & Std. Deviation & Skewness & \multicolumn{1}{c|}{ Kurtosis } \\
\hline Human Resource Management & 5.217 & .6023 & -.038 & 1.642 \\
Quality Management \& Analytics & 5.186 & .98901 & -.975 & 1.353 \\
Customer Satisfaction & 5.624 & .76088 & -.628 & .607 \\
\hline
\end{tabular}

\section{Composite Reliability and Convergent Validity}

To assess the internal consistency reliability of the construct, the composite reliability (CR) was calculated. This was done following the Hair et al., (2016) directions that all items' loadings for reflective constructs should exceed a cutoff value of 0.5 . It is provided in the below table 2 that study items were sufficiently loaded on their relevant constructs item. The values for all item loadings were more than the guided cutoff value of 0.5 . The loadings were ranging from 0.692 to 0.901 , which showed that more than half of the variance in the experimental variable is explained by the constructs themselves. was determined in order to assess convergent validity. The Table 4 also provide convergent validity through average variance 
extracted (AVE) approach, which point out that the AVE values of related latent constructs were exceeded than the minimum required value of 0.5 and the values were found to be in the range of 0.596 to 0.807 AVE values greater than 0.5 elaborate that the latent construct described more than half of the variance of its indicators.

Table: 3 Convergent Validity

\begin{tabular}{|c|c|c|c|c|c|}
\hline $\begin{array}{l}1^{\text {st }} \text { order } \\
\text { Constructs }\end{array}$ & $\begin{array}{l}2^{\text {nd }} \text { order } \\
\text { Constructs }\end{array}$ & Items & Loadings & CR & AVE \\
\hline \multirow[t]{8}{*}{ HRM } & & HRM1 & 0.796 & 0.91 & 0.596 \\
\hline & & HRM2 & 0.742 & & \\
\hline & & HRM3 & 0.813 & & \\
\hline & & HRM4 & 0.794 & & \\
\hline & & HRM5 & 0.849 & & \\
\hline & Q. Analytics & PA & 0.886 & 0.93 & 0.807 \\
\hline & & $\mathrm{OA}$ & 0.794 & & \\
\hline & & $\mathrm{DA}$ & 0.901 & & \\
\hline \multirow[t]{7}{*}{ Customer Satisfaction } & & CS1 & 0.751 & 0.92 & 0.669 \\
\hline & & $\mathrm{CS} 2$ & 0.692 & & \\
\hline & & $\mathrm{CS} 3$ & 0.887 & & \\
\hline & & $\mathrm{CS} 4$ & 0.863 & & \\
\hline & & CS5 & 0.828 & & \\
\hline & & CS6 & 0.784 & & \\
\hline & & CS7 & 0.861 & & \\
\hline
\end{tabular}

\section{Discriminant Validity}

Discriminant validity was also determined for the study through two measures that are cross-loadings and Heterotrait-monotrait (HTMT) criterion. The cross-loadings of all items were determined which need to be 0.5 or higher and ideally 0.7 or higher as per the Hair et al., (2011);

Heterotrait-monotrait ratio of correlations (HTMT) was deployed in the study which is regarded by Henseler et al., (2015) as the superior than prior methods to assess discriminant validity. Table 4 highlight the HTMT ratio for first-order constructs whereas Table 1.4 shows the HTMT ratio for second-order constructs. Both of these tables demonstrate that all the square root of the AVE values were greater than other correlation values between the latent variables, this indicates that a number of constructs used in the study model relate to distinct entities.

Table 4: HTMT Ratio $1^{\text {st }}$ Order Constructs

\begin{tabular}{|llllll|}
\hline & DA & HRD & OA & PDA & PM \\
\hline DA & & & & & \\
HRD & 0.746 & & & & \\
OA & 0.862 & 0.764 & & & \\
PDA & 0.871 & 0.796 & 0.869 & & \\
PM & 0.835 & 0.782 & 0.847 & 0.784 & \\
\hline
\end{tabular}

Table 5: HTMT Ratio $2^{\text {nd }}$ Order Constructs

\begin{tabular}{|llll|}
\hline & QA & HRM & CS \\
\hline QA & & & \\
HRM & 0.879 & & \\
CS & 0.881 & 0.843 & \\
\hline
\end{tabular}


As given in the below table 6 the condition of the R2 of endogenous variables with two or more exogenous latent variables need to be minimum at substantial level, the condition was qualified in this study (Henseler et al., 2015).

Table 6: Coefficient of Determination

\begin{tabular}{|lll|}
\hline & R Square & Effect Size \\
\hline Business Analytics & 0.771 & Substantial \\
Performance Management & 0.767 & Substantial \\
\hline
\end{tabular}

H1: Human Resource management has positive impact on customer satisfaction.

H2: Human Resource management has positive impact on Quality Management \& Analytics Practices H3: Quality management \& Analytics has positive impact on customer satisfaction H4: Quality Management \& Analytics mediates the positive relationship between human resource management and customer satisfaction management.

Table 7: Results of Direct Relationship

\begin{tabular}{|llccccccc|}
\hline & & Beta & SE & T & P & LL & UL & Decision \\
\hline H1 & HRM -> CS & 0.017 & 0.049 & 0.327 & 0.413 & -0.073 & 0.211 & Not-Supported \\
H2 & HRM -> QMA & 0.526 & 0.101 & 5.207 & 0 & 0.386 & 0.627 & Supported \\
H3 & QMA -> CS & 0.616 & 0.137 & 4.496 & 0 & 0.352 & 0.504 & Supported \\
\hline
\end{tabular}

Table 8: Indirect Effects

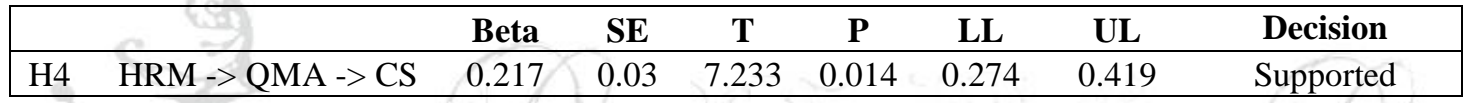

Hypothesis 1: Human Resource management has positive impact on customer satisfaction.

Outcome of the PLS-SEM t of algorithm and bootstrapping found as ; the t-value 0.327 that is less than 1. 645 cutoff value. So, statistically insignificant relationship was resulted among HRM and customer satisfaction. On the basis of provided results (table 1.6), Hypothesis 1 could not receive empirical support, so was rejected. As the needed activities related to sampling and measurement methodology were well taken into account, and the power of analysis ( $\mathrm{G}^{*}$ power) was more than 0.80 , the insignificant relationship could not be linked to the methodological issues.

\section{Hypothesis 2: Human Resource management has positive impact on Quality Management \& Analytics Practices}

As highlighted in the table 1.6 the significant and positive relationship was confirmed among the HRM and QMA practices $(\beta=0.616, \mathrm{t}=5.207, \mathrm{P}=0)$. Therefore, it is supported.

\section{Hypothesis 3: Quality management \& Analytics has positive impact on customer satisfaction}

As per given data in the table 1.6 the significant and positive relationship was also confirmed among the QMA practices and Customer satisfaction $(\beta=0.526, \mathrm{t}=4.496, \mathrm{P}=0)$. So, the hypothesis is supported.

Hypothesis 4: Quality Management \& Analytics mediates the positive relationship between human resource management and customer satisfaction management

Similarly under table 1.6's provided results, the mediation effect of quality management analytics on the relationship between HRM and customer satisfaction was statistically significant $(\beta=0.217, \mathrm{t}=7.233, \mathrm{P}=$ $0)$. Under the condition the hypothesis was found supported. 


\section{Discussion and conclusion}

Although the impact of well-defined HRM practices on employee satisfaction and job performance was confirmed by earlier studies Danish, R.Q et al. (2010), Singh, V. et al. (2018) but the findings of current study are not supporting the direct effect of HRM on customer satisfaction. This has led to further research on knowing what factor if associated with HRM can help enhance customer satisfaction.

Human Resource management has significant and positive impact on Quality Management \& Analytics Practices in the service sector of Punjab province of Pakistan. The previous studies conducted both in service and production entities sector also confirm this outcome (Pham, H. 2020, Alina-Rodica 2019, Shahnawaz, 2006). In this way, HRM was found very useful to improve quality management and analytics implementation and performance in organizations of all sizes in service sector organizations.

The study support that HRM practices also help to enhance use of innovative applications in quality management analytics over the period if employees concern and usability issues are adequate measured (Martin-Rios 2017).In this it was found if HRM practices are taken due care they may help advance the plan, operation and delivery performance operations of the organizations.

Likely Quality Management \& Analytics practices application has significant and positive influence on customer satisfaction in the service sector of selected cities in Punjab. Some studies in the past found determining the linkage between business analytics and customer satisfaction. One of studies recently conducted elaborates that data analytics practices help better articulate the plan and execution processes (Raguseo et al., 2018). It was discussed the pattern previously unknown were discovered by applying analytics tools at measuring and enhancing customer value. As per the study supply chain operations were considerably improved by integrating analytics with operational activities.

Current study has also confirmed that Quality Management \& Analytics mediates the significant positive relationship between human resource management and customer satisfaction management in service sector organizations of the province. Chernetska, (2017) and Raguseo et al., (2018). The analytics practices have been found effectively and efficiently developing new patterns of customer related information in alignment with human resource management tools (Wang, 2018). The patterns were created by deploying, analyzing and retrieving useful information from data though a systematic handling of organization's analytics capabilities.

\section{Recommendations, Future Research Directions and Limitations}

The theoretical gap identified in this study was absence of a well-articulated quality management and analytics body of knowledge that can be used as a basis to integrate QMA with HRM or other disciplines for better service and firm performance. This will also support in accurately integrating current quality management practices with business analytics tools to show up a brand new discipline Quality analytics. The practical implication provided by this study was cross orientation for teams i.e. operational staff need to provide customer service environment orientation and customer service staff should be given base level operation orientation though customized customer surveys or operational processes visits. Second practical implication taken from the study was organizational leaders and professionals need to identify which specific aspects of the job description or work instructions concerning services delivery create value for customer by providing unforgettable experience from HR performance. This linkage has not been found in known previous literature. So, this must be developed for each separate function and level in organizations. The study limitations are given here as; Quality management and analytics led HRM is relatively a new phenomenon. Currently there are very few studies on the topic which have covered some elements with varied objectives not related to the current model. 
It is suggested to conduct the study in different settings, fields and industries. The comparative studies of provinces may be helpful in knowing characteristics of employee job functions closely related to aspects of customer service that may enhance satisfaction. Currently, the cross-sectional method was deployed to gather feedback from target respondents. So, future studies may be conducted with longitudinal approach to determine strength of proposed model as well as know model stability across time in various areas.

\section{References}

Ahmad, K., JianMing, Z. and Rafi, M. (2019), "An analysis of academic librarians competencies and skills for implementation of Big Data analytics in libraries", Data Technologies and Applications, Vol. 53 No. 2, pp. 201-216.

Ahmed, A. O., \& Idris, A. A. (2020). Examining the relationship between soft total quality management (TQM) aspects and employees' job satisfaction in "ISO 9001" Sudanese oil companies. The TQM Journal.

Alina-Rodica, G. A. L. (2019). The Impact Of Quality Management System On The Effectiveness Of Hrm Practices In Sme'S. In Proceedings of the INTERNATIONAL MANAGEMENT CONFERENCE (Vol. 13, No. 1, pp. 863-870). Faculty of Management, Academy of Economic Studies, Bucharest, Romania.

Beck-Krala E., and Scott D. (2014). Research design for compensation systems evaluation, 4th European Reward Management Conference (RMC 2013), Brussels, European Institute for Advanced Studies in Management.

Bontis, N., Booker, L. D., \& Serenko, A. (2007). The mediating effect of organizational reputation on customer loyalty and service recommendation in the banking industry. Management decision, 45(9), $1426-1445$.

Burma, Z. (2014). Human resource management and its importance for today's organizations. International Journal of Education and Social Science, 1(2), 85-92.

Chernetska, D. (2017). Expanding frontiers of customer knowledge management to sustain competitive advantage: The mediating role of predictive analytics. Eurasian Journal of Business and Management, 5(1), 1-15.

Danish, R.Q. and Usman, A. (2010), "Impact of reward and recognition on job satisfaction and motivation: an empirical study from Pakistan", International Journal of Business and Management, Vol. 5 No. 2, pp. $159-167$

David, R. (2013). Strategic management, A Competitive Advantage Approach (Concepts \& Cases). 14th Ed., New Jersey, United States of America: Prentice Hall, Pearson Education

Ekawati, A. D. (2019). Predictive analytics in employee churn: A systematic literature review. Journal of Management Information and Decision Sciences, 22(4), 387-397.

Fitz-Enz, J., \& John Mattox, I. I. (2014). Predictive analytics for human resources. John Wiley \& Sons.

Goetsch, D.L., Davis, S.B., 2016. Quality Management: Introduction to Total Quality Management for Production, Processing, and Services, fifth ed Prentice Hall, New Jersey.

Gopinath, R. and Shibu, S. (2016). Compensation management and welfare measure influencing job satisfaction. A study with reference to Bsnl, Madurai Ssa, Doi: 10.13140/Rg.2.1.2927.6641.

Hair, J. F., Ringle, C. M., \& Sarstedt, M. (2011). PLS-SEM: Indeed a silver bullet. Journal of Marketing theory and Practice, 19(2), 139-152.

Hair, J., Hult, G. T. M., Ringle, C., \& Sarstedt, M. (2016). A primer on partial least squares structural equation modeling (PLS-SEM): Sage Publications.

Hassouna, M., Tarhini, A., Elyas, T., \& Abou Trab, M. S. (2015) Customer churn in mobile markets: a comparison of techniques. International Business Research, 8(6), 224-237.

Henseler, J., Ringle, C. M., \& Sarstedt, M. (2015). A new criterion for assessing discriminant validity in variance-based structural equation modeling. Journal of the academy of marketing science, 43(1), 115135.

Hindle, G., Kunc, M., Mortensen, M., Oztekin, A., \& Vidgen, R. (2020). Business analytics: defining the field and identifying a research agenda. 
Liu, L., Akkineni, S., Story, P., \& Davis, C. (2020, April). Using HR Analytics to Support Managerial Decisions: A Case Study. In Proceedings of the 2020 ACM Southeast Conference (pp. 168-175).

Longenecker, C., and Fink, L. (2013). Creating human resource management value in the twenty first century: seven steps to strategic HR. Human Resource Management International Digest, 21(2), 29-32.

Majumdar, J. P., \& Manohar, B. M. (2016). Why Indian manufacturing SMEs are still reluctant in adopting total quality management. International Journal of Productivity and Quality Management, 17(1), 1635.

Martin-Rios, C., Pougnet, S., \& Nogareda, A. M. (2017). Teaching HRM in contemporary hospitality management: a case study drawing on HR analytics and big data analysis. Journal of teaching in travel \& tourism, 17(1), 34-54.

Obeidat, Bader; Al-Khateeb; Tawalbeh, Hadeel Fareed; Masa'deh, Ra'ed; Akour, Mohammed Ali (2019); Reviewing the Literature among Human Resource Management (HRM) Practices, Total Quality Management (TQM) Practices and Competitive Advantages; Journal of Social Sciences (COES\&RJJSS), Vol.8, No.2, pp:327-358; https://doi.org/10.25255/jss.2019.8.2.327.358.

Pambreni, Y., Khatibi, A., Azam, S., \& Tham, J. (2019). The influence of total quality management toward organization performance. Management Science Letters, 9(9), 1397-1406.

Pham, H. (2020). Impact of human resource management practices on enterprises' competitive advantages and business performance: Evidence from telecommunication industry. Management Science Letters, 10(4), 721-732.

Raguseo, E., \& Vitari, C. (2018). Investments in big data analytics and firm performance: an empirical investigation of direct and mediating effects. International Journal of Production Research, 56(15), 5206-5221.

Rendall, R., Castillo, I., Lu, B., Colegrove, B., Broadway, M., Chiang, L. H., \& Reis, M. S. (2018). Imagebased manufacturing analytics: Improving the accuracy of an industrial pellet classification system using deep neural networks. Chemometrics and Intelligent Laboratory Systems, 180, 26-35.

Shahnawaz, M., and Juyal, R. (2006). Human resource management practices and organizational commitment in different organizations. Journal of the Indian Academy of Applied Psychology, 32(2), 171-178

Sharma, R., Singh, S. P., \& Rana, G. (2019). Employer branding analytics and retention strategies for sustainable growth of organizations. In Understanding the role of business analytics (pp. 189-205). Springer, Singapore.

Singh, V., Kumar, A., \& Singh, T. (2018). Impact of TQM on organizational performance: the case of Indian manufacturing and service industry. Operations Research Perspectives, 5, 199-217

Trkman, P., McCormack, K., De Oliveira, M. P. V., \& Ladeira, M. B. (2010). The impact of business analytics on supply chain performance. Decision Support Systems, 49(3), 318-327.

Wang Y, Kung L, Byrd TA. Big data analytics: understanding its capabilities and potential benefits for healthcare organizations. Technol Forecast Soc Chang. 2018;126:3-13. 